International Journal of Cancer Studies \& Research (IJCR)

$1 S S N: 2167-9118$

\title{
Kaposi Sarcoma of Spleen in HIV-Negative Patient Detected with F-18 FDG PET/CT
}

\author{
Case Report
}

Kang S

Department of Nuclear Medicine, Catholic University of Daegu School of Medicine, Korea.

\section{Abstract}

We report a case of Kaposi sarcoma (KS) who presented with unusual clinical features. The unusual clinical features were abscence of detectable HIV, absence of cutaneous lesion and presence of a splenic mass. F-18 FDG PET/CT demonstrated a spleen mass lesion with FDG uptake with SUVmax 7.0. This lesion was confirmed by ultrasonography guided biopsy. The lesion was consistent with KS. F-18 FDG PET/CT may be instrumental in establishing a diagnosis of the splenic KS.

Keywords: Kaposi Sarcoma; Spleen; F-18 FDG PET/CT; HIV-Negative.

\section{*Corresponding Author:}

Sungmin Kang M.D,

Department of Nuclear Medicine, Catholic University of Daegu School of Medicine 3056-6, Daemyung 4-Dong, Nam-Gu, Daegu 705-718,

Korea.

Tel: +82-53-650-4954

E-mail: kufa77@hanmail.net

Received: August 26, 2015

Accepted: October 01, 2015

Published: October 06, 2015

Citation: Kang S (2015) Kaposi Sarcoma of Spleen in HIV-Negative patient Detected with F-18 FDG PET/CT. Int J Cancer Stud Res. 4(6), 88-90. doi: http://dx.doi.org/10.19070/2167-9118-1500014

Copyright: Kang $\mathbf{S}^{\odot}$ 2015. This is an open-access article distributed under the terms of the Creative Commons Attribution License, which permits unrestricted use, distribution and reproduction in any medium, provided the original author and source are credited.

\section{Introduction}

Focal splenic masses are encountered in routine clinical practice and pose a diagnostic dilemma. A splenic lesion may be discovered incidentally on imaging studies performed for other diseases. Malignant solid splenic lesions include leukemic infiltrates, lymphoma, metastases and rarely, angiosarcoma [1-4].

Moritz Kaposi first described Kaposi sarcoma (KS) in 1872 [5]. Clinically, KS forms dark blue or purplish macular lesions or spindle shaped nodular lesions that occur in the skin, lymphoid, respiratory and gastrointestinal tissues, in networks of spindle shaped cells and in vascular spaces surrounded by an endothelial cell layer on histological imaging [6]. KS occurs most frequently in mucocutaneous sites, typically the skin of the lower extremities, face, trunk, genitalia and oropharyngeal mucosa. KS also commonly involves lymph nodes and visceral organs, most notably the respiratory and gastrointestinal tracts [7]. But splenic involvement of KS is very infrequent and is clinically unexpected [8]. The diagnostic approach to splenic involvement of KS is difficult because most procedures have a poor diagnostic yield.

The role of F-18 fluorodeoxyglucose positron emission tomography/computed tomography (FDG PET/CT) in oncological imaging is well established. It has high sensitivity and specificity for many malignancies [9-12] and may help reveal unexpected sites of $\mathrm{KS}$, because of its ability to scan the whole body. The literature regarding the role of F-18 FDG PET/CT imaging for the evaluation of visceral and lymphatic involvement and staging in various types of $\mathrm{KS}$ are scant $[13,14]$.

We report the detection of KS in spleen using F-18 FDG PET/ CT in a human immunodeficiency virus (HIV)-negative patient.

\section{Case Report}

A 48-year-old male was seen in June 2011 because of anemia, dyspnea, abdominal discomfort and jaundice. His complete blood count on admission was as follows: white blood cell $10000 / \mu \mathrm{L}$, hemoglobin $8.0 \mathrm{~g} / \mathrm{dL}$ and platelet $18600 / \mu \mathrm{L}$. The result of liver function tests were elevation of glutamic oxaloactic transaminase, glutamic pyruvate transaminase, bilirubin and depression of serum protein and albumin. Contrast-enhanced abdominal CT scan showed a $4.0 \mathrm{~cm}$ sized mass lesion in the spleen with mild enhancement. F-18 FDG PET/CT was performed to search for other malignant diseases. Mass lesion displayed FDG uptake with maximum standardized uptake value (SUVmax) 7.0 (Figure 1). For diagnosis, ultrasonography guided biopsy was performed. The section showed vascular channels filled red blood cells and infiltration of atypical spindle and epitheloid cells with angiomatous proliferation of vessel. On immunohistochemical investigation, 100\% immunoreactivity for CD31 was found which supported the final diagnosis. These findings were consistent with KS (Figure 2). The patient was HIV-negative using a macro-enzyme immunoassay.

\section{Discussion}

KS can be classified into different clinical and epidemiological 
Figure 1. F-18 FDG PET/CT showed hepatomegaly and increased uptake in mass lesion at anatomical region of the spleen (SUVmax $=7.0$, red arrow) which was proven to be Kaposi sarcoma by histological examination.

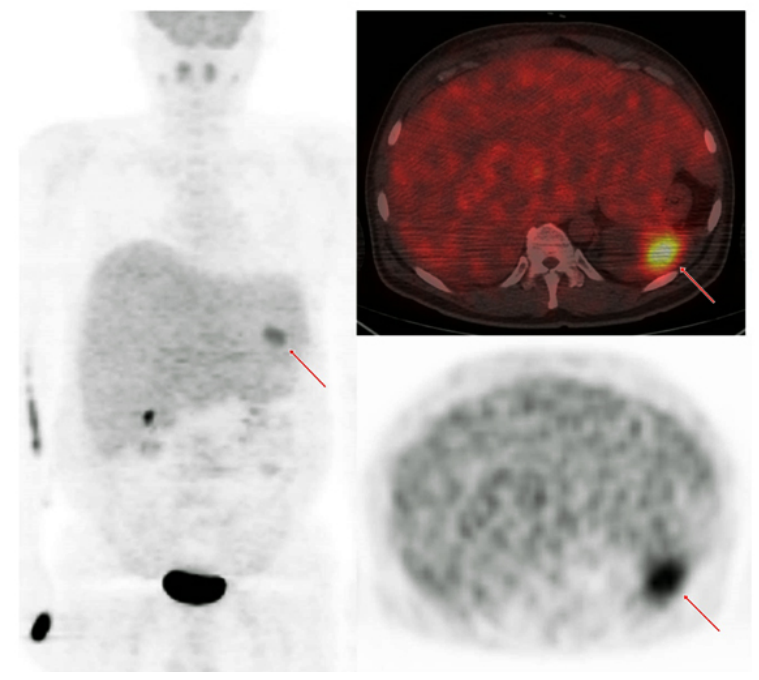

Figure 2. Histological diagnosis (magnification $X$ 100): The section showed vascular channels filled red blood cells and infiltration of atypical spindle and epitheloid cells with angiomatous proliferation of vessel. Immunohistochemical stains were obtained, which were strongly positive for CD31 confirming the diagnosis of a Kaposi sarcoma.

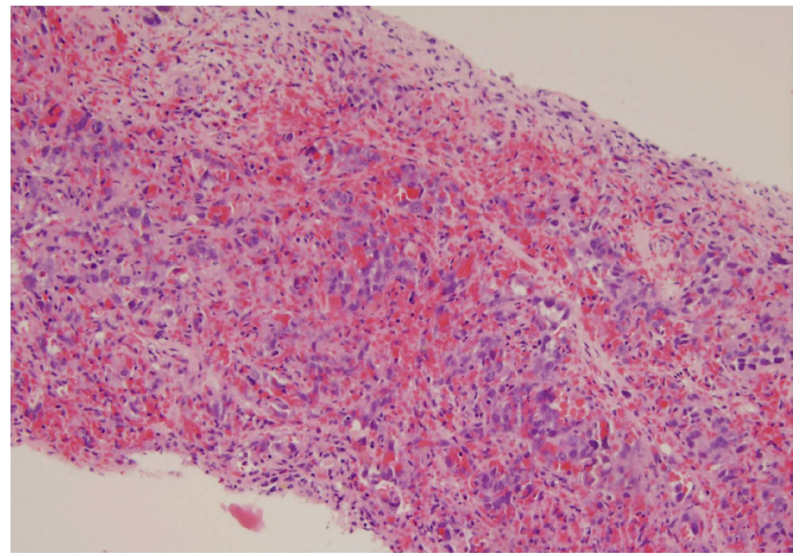

forms. The indolent form of $\mathrm{KS}$ is frequently observed in elderly male patients of Mediterranean or Eastern Europe origin, usually affecting the lower extremities and rarely involving visceral organ [15]. The mild form is also observed in organ-transplant recipients and patients treated with immunosuppressive therapy for various medical conditions [16]. The endemic and aggressive form involving visceral and lymphatic organs is observed in young adults and children of sub-equatorial Africa [17]. The most aggressive form is observed in HIV-positive patients, especially homosexual or bisexual men, where it is generalized and disseminated localizing in skin and visceral organs including the gastrointestinal tract and lung [18]. Occurrence of HIV-negative KS is rare and has to be distinguished from AIDS associated KS [19]. The prevalence rate of HIV-negative KS varies according to personal factors such as race, sex, age and immune status of the patient. Jakob et al reported that only 20 cases of HIV-negative KS in German patient between 1987 and 2009 and concluded that HIV-negative KS is a localized process that rarely involves lymph nodes or organs, and is mostly seen in older males from Mediterranean or Eastern European countries and is responsive on local or systemic therapeutic strategies [19]. The incidence of HIV-negative KS in East Asia including Korea is unknown.

In normal individuals, F-18 FDG uptake in the spleen is less than that in the liver and splenic uptake greater than hepatic uptake is considered abnormal [20]. F-18 FDG PET/CT has a very high sensitivity (92\%-100\%) for detecting splenic disease in lymphoma [21] and is effective in detecting clinically occult KS lesions that are difficult to diagnose with standard imaging techniques in more advanced stages of KS [22]. So the technique is useful in distinguishing $\mathrm{KS}$ as a malignant lesion and can correctly localize the appropriate site for biopsy [23]. In our case, F-18 FDG PET/CT detected the rare occurrence of splenic KS, which was confirmed by biopsy.

In summary, this case reports a splenic KS that was detected early using F-18 FDG PET/CT in a HIV-negative patient. F-18 FDG PET/CT may be instrumental in establishing a diagnosis of splenic KS.

\section{Ethical Standard}

A waiver of institutional review board approval was obtained for this case report.

\section{References}

[1]. Bragg DG, Colby TV, Ward JH (1986) New concepts in the non-Hodgkin lymphomas: radiologic implications. Radiology 159(2): 291-304.

[2]. Kutok JL, Fletcher CD (2003) Splenic vascular tumors. Semin Diagn Pathol 
20(2): 128-139.

[3]. Lee SS, Morgenstern L, Phillips EH, Hiatt JR, Margulies DR (2000) Splenectomy for splenic metastases: a changing clinical spectrum. Am Sur 66(9): 837-840.

[4]. Paterson A, Frush DP, Donnelly LF, Foss JN, O'Hara SM, et al. (1999) A pattern-oriented approach to splenic imaging in infants and children. Radiographics 19(6): 1465-1485.

[5]. Mukai MM, Chaves T, Caldas L, Neto JF, Santamaria JR (2009) Primary Kaposi's sarcoma of the penis. An Bras Dermatol 84(5): 524-526.

[6]. Brash DB, Bale AE (2000) Molecular biology of skin cancer. In Cancer Principles and Practice of Oncology. Lippincott Williams \& Wilkins, Philadelphia. 1971-1975.

[7]. Mitsuyasu RT (1987) Clinical variants and staging of Kaposi's sarcoma. Semin Oncol 14(2 Suppl 3): 13-18.

[8]. Niedt GW, Schinella RA (1985) Acquired immunodeficiency syndrome. Clinicopathologic study of 56 autopsies. Arch Pathol Lab Med 109(8): 727734

[9]. Cohade C, Osman M, Leal J, Wahl RL (2003) Direct comparison of (18)FFDG PET and PET/CT in patients with colorectal carcinoma. J Nucl Med 44(11): 1797-1803.

[10]. Lardinois D, Weder W, Hany TF, Kamel EM, Korom S, et al. (2003) Staging of non-small-cell lung cancer with integrated positron-emission tomography and computed tomography. N Engl J Med 348(25): 2500-2507.

[11]. Moog F, Bangerter M, Diederichs CG, Guhlmann A, Merkle E, et al. (1998) Extranodal malignant lymphoma: detection with FDG PET versus CT. Radiology 206(2): 475-481.

[12]. Schwimmer J, Essner R, Patel A, Jahan SA, Shepherd JE, et al. (2000) A review of the literature for whole-body FDG PET in the management of patients with melanoma. Q J Nucl Med 44(2): 153-167.

[13]. Canbaz F, Ersoy D, Basoglu T (2011) Two cases of 18F-FDG PET/CT find- ings in HIV-negative Kaposi's sarcoma. Original presentation of one case favorably treated with interferon. Hell J Nucl Med 14(1): 74-75.

[14]. Sager S, Engin B, Kutlubay Z, Asa S, Sager SG, et al. (2013) PET/CT imaging of HIV-negative Kaposi's sarcoma. Ir J Med Sci 182(4): 745-746.

[15]. Schwartz RA, Micali G, Nasca MR, Scuderi L (2008) Kaposi sarcoma: a continuing conundrum. J Am Acad Dermatol 59(2): 179-206.

[16]. Penn I (1979) Kaposi's sarcoma in organ transplant recipients: report of 20 cases. Transplantation 27(1): 8-11.

[17]. Taylor JF, Smith PG, Bull D, Pike MC (1972) Kaposi's sarcoma in Uganda: geographic and ethnic distribution. Br J Cancer 26(6): 483-497.

[18]. Haverkos HW, Drotman DP, Morgan M (1985) Prevalence of Kaposi's sarcoma among patients with AIDS. N Engl J Med 312(23): 1518.

[19]. Jakob L, Metzler G, Chen KM, Garbe C (2011) Non-AIDS associated Kaposi's sarcoma: clinical features and treatment outcome. PLoS One 6(4): e18397.

[20]. Liu Y (2009) Clinical significance of diffusely increased splenic uptake on FDG-PET. Nucl Med Commun 30(10): 763-769.

[21]. Rini JN, Leonidas JC, Tomas MB, Palestro CJ (2003) 18F-FDG PET versus $\mathrm{CT}$ for evaluating the spleen during initial staging of lymphoma. J Nucl Med 44(7): 1072-1074.

[22]. van de Luijtgaarden A, van der Ven A, Leenders W, Kaal S, Flucke U, et al. (2010) Imaging of HIV-associated Kaposi sarcoma; F-18-FDG-PET/CT and In-111-bevacizumabscintigraphy. J Acquir Immune Defic Syndr 54(4): 444-446.

[23]. Castaigne C, Tondeur M, de Wit S, Hildebrand M, Clumeck N, et al. (2009) Clinical value of FDG-PET/CT for the diagnosis of human immunodeficiency virus-associated fever of unknown origin: a retrospective study. Nucl Med Commun 30(1): 41-47. 